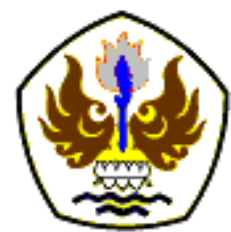

INFOMATEK

Volume 23 Nomor 1 Juni 2021

\title{
PENENTUAN DOSIS OPTIMUM NATRIUM HIPOKLORIT PADA PROSES KLORINASI INSTALASI PENGOLAHAN AIR LIMBAH PERUSAHAAN FARMASI
}

\author{
Purnomosutji Dyah Prinajati $^{\star}$ \\ Program Studi Teknik Lingkungan \\ Universitas Sahid Jakarta
}

\begin{abstract}
Abstrak: Perusahaan farmasi yang turut andil dalam menjaga lingkungan. Salah satu upaya yang dilakukan adalah dengan membangun Instalasi Pengolahan Air Limbah (IPAL). Pengembangan Instalasi Pengolahan Air Limbah (IPAL) pun terus dilakukan oleh Perusahaan Farmasi, agar selalu dapat memenuhi baku mutu yang ditetapkan oleh Pemerintah. Oleh Karena itu, dibangun unit klorinasi dengan menambahkan bahan kimia klorin pada Instalasi Pengolahan Air Limbah (IPAL) pada Perusahaan Farmasi. Namun, apabila penggunaan klorin pada unit klorinasi tidak tepat maka akan menimbulkan dampak bagi lingkungan. Karena hal tersebut, dilakukan penelitian penentuan dosis optimum klorin pada unit klorinasi untuk mendapatkan dosis optimum klorin dari nilai bebas klorin yang tidak melebihi baku mutu klorin bebas dalam air limbah. Penentuan konsentrasi dosis optimum klorin dilakukan dengan metode Jartest. Berdasarkan hasil dari penelitian yang dilakukan maka ditetapkan konsentrasi dosis optimum klorin yang ditambahkan pada unit klorinasi pada Perusahaan Farmasi ini sebesar 6 $\mathrm{mg} / \mathrm{L}$.
\end{abstract}

Kata kunci: instalasi pengolahan air limbah, jartest, klorinasi, klorin bebas

\section{PENDAHULUAN}

Industri manufaktur mengalami peningkatan produksi sebesar 4,33\% berdasarkan Badan Pusat Statistik Indonesia tahun 2017. Peningkatan produksi tersebut salah satunya disebabkan oleh meningkatnya produksi pada industri farmasi. Industri farmasi merupakan salah satu industri yang menghasilkan limbah, baik limbah padat maupun limbah cair

\footnotetext{
*) iinsoekandar@gmail.com

Pertama diterima: 16 April 2021

Direvisi: 19 April 2021

Disetujui untuk publikasi: 17 Mei 2021
}

(Crisnaningtyas dkk, 2016 [1]). Limbah adalah buangan yang kehadirannya pada suatu saat dan tempat tertentu tidak dikehendaki lingkungan karena tidak memiliki nilai ekonomi. Apabila limbah yang dihasilkan dibuang ke dalam badan air tanpa proses pengolahan terlebih dahulu, maka akan menjadi sumber pencemar bagi lingkungan (Yustiani, 2016 [2]). Oleh karena itu, setiap industri harus menjaga kualitas lingkungan dari limbah yang dihasilkan dengan upaya pengelolaan lingkungan yang baik (Yustiani 
dkk, 2017 [3]). Salah satu industri farmasi yang melakukan upaya pengelolaan lingkungan.

Perusahaan Farmasi ini merupakan salah satu perusahaan farmasi ternama di Indonesia yang berdiri sejak tahun 1970. Dalam kegiatan produksinya, menghasilkan limbah berupa limbah cair sebagai hasil pengolahan proses produksi serta kegiatan domestik dari industri dan kantor (Meirdana \& Utomo, 2021 [4]). Perusahaan Farmasi ini telah berupaya dalam pengendalian pencemaran lingkungan, dengan membangun unit pengolahan air limbah yang dapat mengolah air limbah yang dihasilkan serta telah berupaya melakukan pemantauan terhadap kualitas dari hasil pengolahan air limbah, agar tetap memenuhi baku mutu sesuai dengan peraturan pemerintah yang berlaku, yaitu Peraturan Gubernur No.69 Tahun 2013 dan Peraturan Gubernur No.122 Tahun 2005.

Namun, pada Bulan Agustus 2016 Menteri Lingkungan Hidup dan Kehutanan Republik Indonesia telah menetapkan baku mutu yang baru tentang air limbah domestik yang tertuang dalam Peraturan Menteri Lingkungan Hidup dan Kehutanan Republik Indonesia Nomor P.68/ Menlhk/ Setjen/ Kum.1/ 8/ 2016. Dari parameter baku mutu air limbah domestik yang tertuang dalam PerMen LHK No. 68 Tahun 2016 terdapat penambahan parameter kualitas air limbah bila dibandingkan dengan baku mutu yang tertuang pada Peraturan Gubernur No.122 Tahun 2005, yaitu parameter total bakteri koliform dengan nilai batas maksimum sebesar 3000 jumlah/100 ml. Kurangnya sosialisasi dari pemerintah membuat Perusahaan Farmasi ini baru mengetahui peraturan tersebut pada bulan Pebruari 2017. Sehingga pada bulan September 2016 sampai dengan Januari 2017, pengukurankualitas air limbah tidak mengacu baku mutu yang tertuang pada Peraturan Menteri Lingkungan Hidup dan Kehutanan Nomor 68 Tahun 2016. Pengukuran kualitas air limbah pada bulan Pebruari 2017 baru mengacu pada baku mutu Peraturan Menteri Lingkungan Hidup dan Kehutanan Nomor 68 Tahun 2016, namun hasil dari pengujian kualitas air limbah bulan Pebruari 2017 terdapat 1 parameter yang melebihi baku mutu yaitu parameter total bakteri koliform dengan hasil pengukuran sebesar $>3000$ jumlah/100 ml.

Hal ini membuat pihak perusahaan memutuskan untuk menambah unit klorinasi dengan konsentrasi larutan Natrium Hipoklorit ( $\mathrm{NaClO}$ ) sebesar $20 \mathrm{mg} / \mathrm{L}$ dan menghasilkan nilai klorin bebas sebesar $1,53 \mathrm{mg} / \mathrm{L}$ yang bila 
dibandingkan dengan baku mutu klorin bebas memiliki nilai klorin bebas yang melebihi baku mutu, karena nilai baku mutu klorin bebas pada Peraturan Gubernur Nomor 69 Tahun 2013 maksimal sebesar 1 mg/L. Oleh karena itu, maka perlu dilakukannya penelitian untuk mengetahui konsentrasi klorin yang efektif untuk dibubuhkan pada IPAL dan tidak melebihi baku mutu klorin bebas.

\section{METODOLOGI}

Penelitian ini adalah penelitian eksperimen. Penelitian dilakukan untuk mendapatkan konsentrasi dosis optimum penambahan klorin dari nilai klorin bebas yang terdapat pada tiap konsentrasi penelitian skala laboratorium. Penelitian ini dilakukan pada Instalasi Pengolahan Air Limbah (IPAL).

Alat-alat yang digunakan dalam penelitian ini antara lain adalah piala gelas, magnetic stirrer, stopwatch, pipet volume, pipet serologi, spectrophotometer spectroquant nova 60 , kertas saring, kuvet, ember plastik, botol gelas steril, dan tabung reaksi. bahan- bahan yang digunakan dalam penelitian ini antara lain adalah air limbah outlet tangki sedimentasi, natrium hipoklorit $12 \% \mathrm{v} / \mathrm{v}$, dan chlorine test.

Data yang dipergunakan dalam penyusunan laporan adalah semua data yang diperoleh seperti data primer, data sekunder, dan data lainnya yang diperlukan. Data primer diperoleh dari hasil observasi atau pengamatan, dokumentasi, wawancara, dan pengukuran langsung yang dilakukan terhadap obyek penelitian yang berkaitan dengan Instalasi Pengolahan Air Limbah.

Data sekunder merupakan data yang diperoleh dengan menelaah dokumendokumen yang ada atau data yang tidak langsung diperoleh peneliti dari subjek penelitiannya yang menunjang data primer.

Pada penelitian ini dilakukan penelitian skala laboratorium dengan cara sebagai berikut:

1. Diambil \pm 20 liter sampel air limbah Outlet tangki sedimentasi menggunakan ember plastik.

2. Dituangkan masing-masing sebanyak 1 liter sampel air limbah ke dalam piala gelas 1 liter.

3. Ditambahkan Natrium Hipoklorit $(\mathrm{NaClO})$ ke dalam setiap piala gelas hingga menghasilkan beberapa variasi konsentrasi $(0$ ppm, 1 ppm, 5 ppm, 10 ppm, 15 ppm, dan 20 ppm).

4. Sampel yang telah dibubuhi $\mathrm{NaClO}$ kemudian ditempatkan di atas magnetic stirrer dan diaduk selama \pm 3 menit dengan kecepatan 45 rpm (rumus 
perhitungan dapat dilihat pada Lampiran

$$
\text { A). }
$$

5. Setelah sampel selesai diaduk, diamkan selama $\pm 1,5$ jam (rumus perhitungan dapat dilihat pada Lampiran A). waktu reaksi tersebut disesuaikan dengan waktu tinggal air limbah dalam IPAL PT Merck Tbk. sebelum dibuang ke perairan umum.

6. Setelah sampel didiamkan sesuai waktu yang ditentukan, saring sampel dengan menggunakan kertas saring berabu untuk memisahkan cairan bening dengan padatan tersuspensi pada sampel air limbah.

7. Sampel yang telah disaring, dipipet masing-masing sebanyak $10 \mathrm{ml}$ sampel ke dalam tabung reaksi kosong berukuran $10 \mathrm{ml}$.

8. Sampel pada tabung reaksi tersebut ditambahkan 1 dosis reagent C/2-1 lalu homogenkan hingga merata dan tunggu untuk waktu reaksi selama 1 menit.

9. Sampel yang telah ditambahkan reagent Cl2-1 kemudian dituangkan ke dalam kuvet ukuran $10 \mathrm{~mm}$.

10. Kuvet yang telah berisi sampel dimasukkan ke dalam alat Spectrophotometer Spectroquant NOVA 60 untuk kemudian diukur konsentrasi klorin bebas pada sampel. (tampilan pada layar alat akan muncul nilai klorin bebas dengan satuan $\mathrm{mg} / \mathrm{L} \mathrm{Cl}$ )

11. Ulangi langkah 2 sampai 9 dengan rentang variasi dosis $\mathrm{NaClO}$ yang lebih kecil hingga didapatkan dosis optimum.

12. Lakukan pengukuran terhadap blanko sampel air limbah dengan mengulang langkah 6 sampai 9 .

Teknik perhitungan data yang digunakan dalam penelitian diantaranya:

a. Pembubuhan Klorin Tiap Variasi Konsentrasi Konsentrasi $\mathrm{NaClO} 12 \% \mathrm{v} / \mathrm{v}=$ $120.000 \mathrm{ppm}(\mathrm{mg} / \mathrm{L}) \mathrm{V} 1 \times \mathrm{C} 1=\mathrm{V} 2 \times \mathrm{C} 2$ Keterangan:

V1 = Volume NaClO 12\% yang ditambahkan C1 = Konsentrasi awal NaClO 12\% V2 = Volume larutan yang dibuat dengan konsentrasi yang diinginkan $\mathrm{C} 2$ = Konsentrasi larutan yang ingin dibuat

b. Perhitungan Jumlah Bakteri Koliform (MPN/100 ml)

MPN Contoh $=\frac{\text { MPN }}{\text { ml ataug }}-\frac{\text { Nilai MPN Tabel }}{100} \times$ factor pengenceran

Penelitian ini dilakukan dalam 2 tahap. Diagram alir tahap 1 dan tahap 2 dapat dilihat pada masing-masing Gambar 1 dan Gambar 2. 


\section{a. Tahap Pertama}

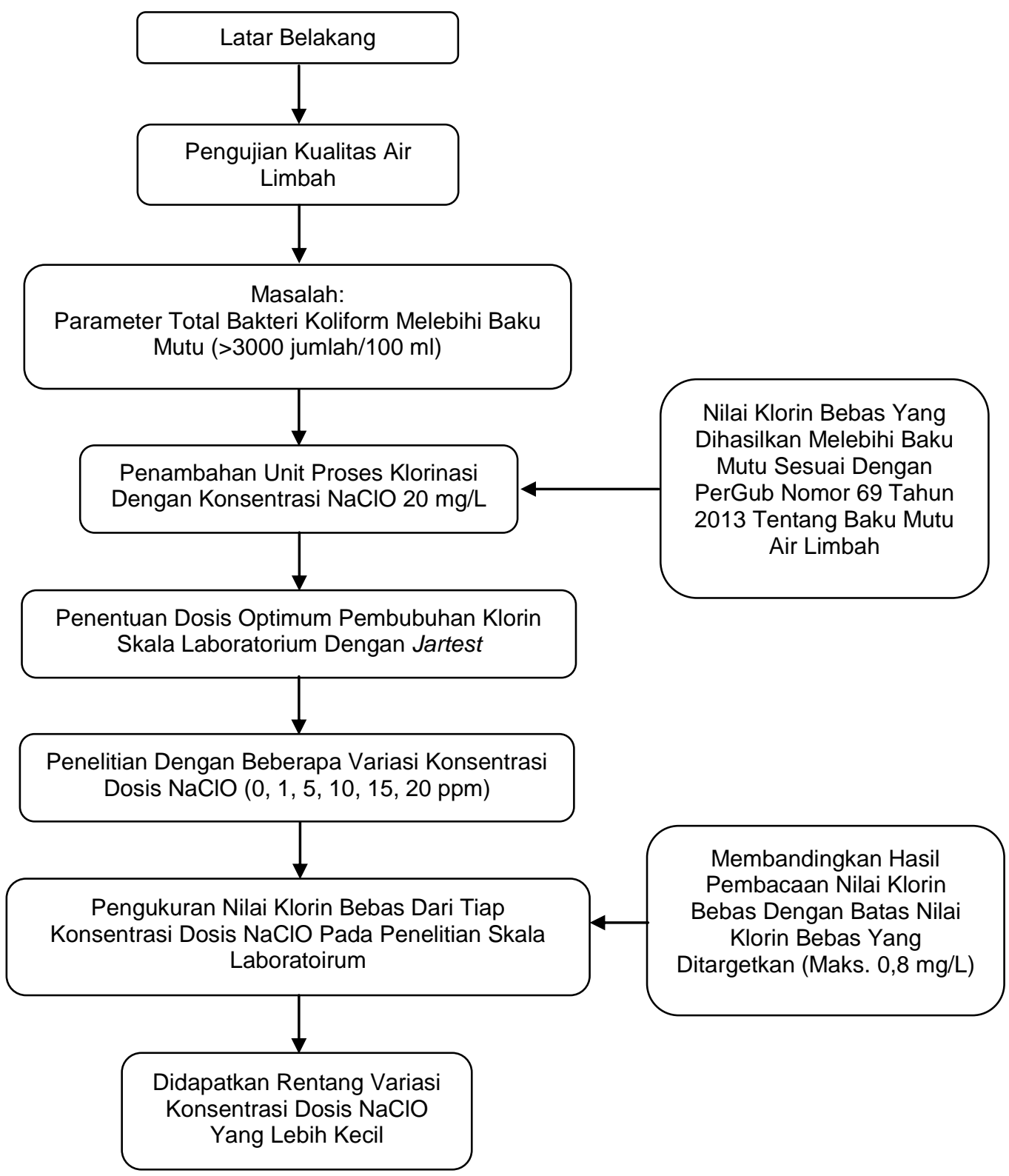

Gambar 1.

Diagram Alir Kegiatan Penelitian Tahap Pertama 
b. Tahap Kedua

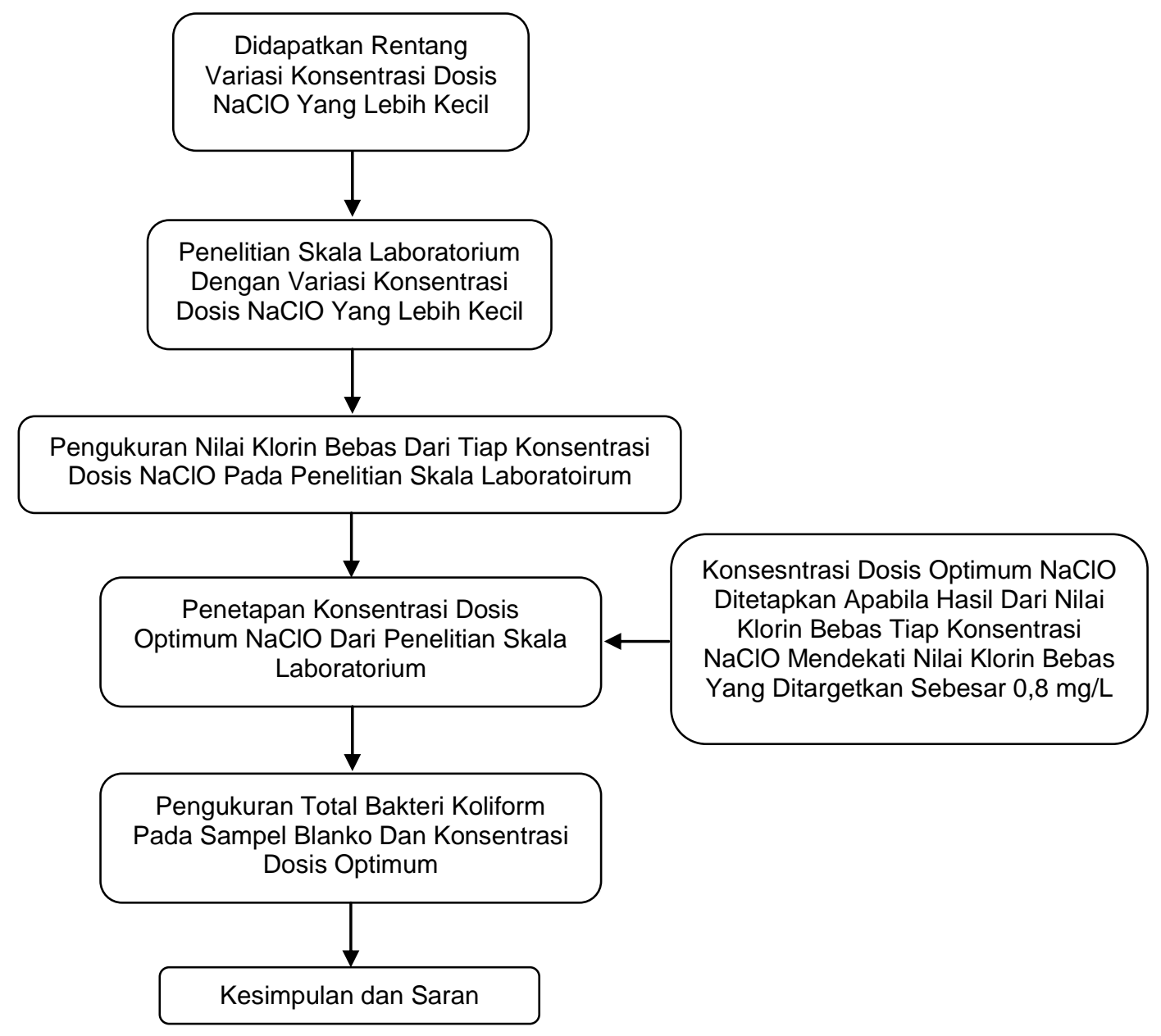

Gambar 2.

Diagram Alir Kegiatan Penelitian Tahap Kedua 
Tabel 1.

MPN Seri 3 Tabung (SNI nomor 06-4158-1996)

\begin{tabular}{|c|c|c|c|c|c|}
\hline \multicolumn{3}{|c|}{$\begin{array}{l}\text { Jumlah tabung } \\
\text { positif }\end{array}$} & \multirow[t]{3}{*}{ MPN/g } & \multicolumn{2}{|c|}{$\begin{array}{c}\text { Batas } \\
\text { kepercayaan } \\
95 \% \\
\end{array}$} \\
\hline 0,1 & 0,01 & 0,001 & & Bawah & Atas \\
\hline $\mathrm{g}$ & $g$ & $g$ & & Lavrain & \\
\hline 0 & 0 & 0 & $<3,6$ & - & 9,5 \\
\hline 0 & 0 & 1 & 3 & 0,15 & 9,6 \\
\hline 0 & 1 & 0 & 3 & 0,15 & 11 \\
\hline 0 & 1 & 1 & 6,1 & 1,2 & 18 \\
\hline 0 & 2 & 0 & 6,2 & 1,2 & 18 \\
\hline 0 & 3 & 0 & 9,4 & 3,6 & 38 \\
\hline 1 & 0 & 0 & 3,6 & 0,17 & 18 \\
\hline 1 & 0 & 1 & 7,2 & 1,3 & 18 \\
\hline 1 & 0 & 2 & 11 & 3,6 & 38 \\
\hline 1 & 1 & 0 & 7,4 & 1,3 & 20 \\
\hline 1 & 1 & 1 & 11 & 3,6 & 38 \\
\hline 1 & 2 & 0 & 11 & 3,6 & 42 \\
\hline 1 & 2 & 1 & 15 & 4,5 & 42 \\
\hline 1 & 3 & 0 & 16 & 4,5 & 42 \\
\hline 2 & 0 & 0 & 9,2 & 1,4 & 38 \\
\hline 2 & 0 & 1 & 14 & 3,6 & 42 \\
\hline 2 & 0 & 2 & 20 & 4,5 & 42 \\
\hline 2 & 1 & 0 & 15 & 3,7 & 42 \\
\hline 2 & 1 & 1 & 20 & 4,5 & 42 \\
\hline 2 & 1 & 2 & 27 & 8,7 & 94 \\
\hline 2 & 2 & 0 & 21 & 4.5 & 42 \\
\hline 2 & 2 & 1 & 28 & 8,7 & 94 \\
\hline 2 & 2 & 2 & 35 & 8,7 & 94 \\
\hline 2 & 3 & 0 & 29 & 8,7 & 94 \\
\hline 2 & 3 & 1 & 36 & 8,7 & 94 \\
\hline 3 & 0 & 0 & 23 & 4,6 & 94 \\
\hline 3 & 0 & 1 & 38 & 8,7 & 110 \\
\hline 3 & 0 & 2 & 64 & 17 & 180 \\
\hline 3 & 1 & 0 & 43 & 9 & 180 \\
\hline 3 & 1 & 1 & 75 & 17 & 200 \\
\hline 3 & 1 & 2 & 120 & 37 & 420 \\
\hline 3 & 1 & 3 & 160 & 40 & 420 \\
\hline 3 & 2 & 0 & 93 & 18 & 420 \\
\hline 3 & 2 & 1 & 150 & 37 & 420 \\
\hline 3 & 2 & 2 & 210 & 40 & 430 \\
\hline 3 & 2 & 3 & 290 & 90 & 1.000 \\
\hline 3 & 3 & 0 & 240 & 42 & 1.000 \\
\hline 3 & 3 & 1 & 460 & 90 & 2.000 \\
\hline 3 & 3 & 2 & 1.100 & 180 & 4.100 \\
\hline 3 & 3 & 3 & $>1.100$ & 420 & - \\
\hline
\end{tabular}

\section{ANALISIS DAN PEMBAHASAN}

Penelitian skala laboratorium dilakukan bertujuan untuk memberikan gambaran dosis klorin yang dibubuhkan pada IPAL secara efisien. Pada Penelitian yang dilakukan dibutuhkan sampel air limbah minimal 20 liter air limbah. Pada penelitian skala laboratorium dilakukan pengadukan menggunakan magnetic stirrer dengan kecepatan $45 \mathrm{rpm}$ selama 3 menit dan larutan didiamkan selama 1,5 jam. Lama waktu 1,5 jam berdasarkan waktu tinggal IPAL pada bak pemilahan sebelum air limbah dipompa keluar dari IPAL.

Pada penelitian ini, penulis melakukan 9 hari penelitian dengan beberapa variasi dosis penambahan hingga mendapatkan konsentrasi dosis optimum pembubuhan klorin pada IPAL.

Pada penelitian ini dilakukan 2 tahap. Tahap pertama yaitu penelitian dengan beberapa variasi konsentrasi yang besar.

Tahap kedua yaitu dilakukannya penelitian dengan beberapa variasi konsentrasi $\mathrm{NaClO}$ dengan rentang yang lebih sempit. Dari konsentrasi dosis optimum yang ditetapkan dilakukan pengujian total bakteri koliform sebanyak satu kali pengujian untuk memastikan adanya penurunan jumlah bakteri koliform dari sampel blanko dan sampel konsentrasi dosis optimum. Pengujian total bakteri kolifrom dilakukan pada trial ke 1. Hasil 
dari semua penelitian dituangkan dalam bentuk table dan grafik untuk dapat menyimpulkan dosis optimum penampanan $\mathrm{NaClO}$ yang aman dan efesien.

Tabel.2.

Hasil Penelitian Tahap Pertama

\begin{tabular}{lllllllllll}
\hline & \multirow{2}{*}{ No. } & Dosis & \multicolumn{10}{c}{ Hasil Pengukuran Klorin Bebas $\mathbf{m g} / \mathbf{L})$} \\
\cline { 3 - 12 } & & Nrial & Trial & Trial & Trial & Trial & Trial & Trial & Trial & Trial \\
\hline 1. & $0 \mathrm{ppm}$ & 0,48 & $\mathbf{2}$ & $\mathbf{3}$ & $\mathbf{4}$ & $\mathbf{5}$ & $\mathbf{6}$ & $\mathbf{7}$ & $\mathbf{8}$ & $\mathbf{9}$ \\
\hline 2. & $1 \mathrm{ppm}$ & 0,54 & 0,60 & 0,62 & 0,68 & 0,61 & 0,52 & 0,55 & 0,49 & 0,53 \\
3. & $5 \mathrm{ppm}$ & 0,73 & 0,77 & 0,69 & 0,93 & 0,79 & 0,57 & 0,56 & 0,61 & 0,66 \\
4. & $10 \mathrm{ppm}$ & 1.14 & 0,93 & 1,08 & 1,12 & 0,89 & 0,94 & 0,85 & 0,75 & 0,71 \\
5. & $15 \mathrm{ppm}$ & 1,23 & 1,19 & 1,17 & 1,21 & 1,09 & 1,16 & 0,98 & 1,17 & 1,11 \\
6. & $20 \mathrm{ppm}$ & 1,34 & 1,47 & 1,25 & 1,22 & 1,11 & 1,23 & 1,13 & 1,23 & 1,27 \\
\hline
\end{tabular}

Berdasarkan Tabel 2 dapat dilihat bahwa nilai klorin bebas yang dihasilkan cenderung meningkat seiring dengan meningkatnya penambahan konsentrasi dosis $\mathrm{NaClO}$ pada sampel air limbah dari setiap hasil penelitian tahap awal. Hasil penelitian tahap awal akan dijadikan dasar untuk menentukan rentang konsentrasi sampel penelitian untuk penelitian tahap kedua.

Pada penelitian skala laboratorium, penulis menetapkanbatas nilai klorin bebas yangdihasilkan dengan safety factor sebesar $20 \%$ dari nilai baku mutu klorin bebas, dalam hal ini berarti batas nilai klorin bebas yang dihasilkan pada setiap penelitian maksimum sebesar 0,8 mg/L. Berdasarkan hasil nilai klorin bebas yang disajikan pada Tabel 2 menunjukkan bahwa rentang konsentrasi dosis opimum berada diantara konsentrasi 5 $\mathrm{mg} / \mathrm{L}$ sampai $10 \mathrm{mg} / \mathrm{L}$. Untuk rentang dari penelitian tahap kedua dari tiap-tiap trial dapat dilihat pada Tabel 3.

Tabel 3.

Rentang Dosis NaClO Pada Penelitian Tahap Kedua

\begin{tabular}{ccl}
\hline No. & Penelitian & $\begin{array}{c}\text { Dosis Penambahan NaClO } \\
\text { (mg/L) }\end{array}$ \\
\hline 1. & Trial 1 & 3,$5 ; 4 ; 4,5 ; 5,5 ;$ dan 6 \\
2, & Trial 2 & $5 ; 6 ; 7 ; 8 ;$ dan 9 \\
3. & Trial 3 & $5 ; 6 ; 7 ; 8 ;$ dan 9 \\
4. & Trial 4 & 1,$5 ; 2 ; 3 ; 3,5 ;$ dan 4,5 \\
5. & Trial 5 & $5 ; 6 ; 7 ; 8 ;$ dan 9 \\
6. & Trial 6 & 1,$5 ; 2 ; 3 ; 3,5 ;$ dan 4,5 \\
7. & Trial 7 & $5 ; 6 ; 7 ; 8 ;$ dan 9 \\
8. & Trial 8 & $5 ; 6 ; 7 ; 8 ;$ dan 9 \\
9. & Trial 9 & $5 ; 6 ; 7 ; 8 ;$ dan 9 \\
\hline
\end{tabular}

Hasil dari Trial tahap kedua disajikan dalam bentuk tabel dan grafik agar memudahkan dalam pembacaan dan penentuan dosis 
optimum $\mathrm{NaClO}$. Berdasarkan hasil penelitian tahap kedua pada Trial 1 menunjukkan bahwa nilai klorin bebas yang dihasilkan sebesar 0,79 $\mathrm{mg} / \mathrm{L}$ berada pada dosis $\mathrm{NaClO}$ sebesar 5,5 $\mathrm{mg} / \mathrm{L}$. Dengan demikian, dosis optimum yang ditetapkan pada Trial 1 sebesar 5,5 mg/L.

Pada Trial 1 dilakukan pengujian total bakteri

Tabel 4. koliform pada sampel blanko dan sampel konsentrasi dosis optimum dengan hasil jumlah bakteri koliform pada sampel blanko sebesar 3000 jumlah/100 mL, sedangkan hasil jumlah bakteri koliform pada sampel konsentrasi dosis optimum sebesar 300 jumlah/100 mL.

Hasil Penelitian Tahap Kedua dari Trial Ke-1

\begin{tabular}{|c|c|c|c|c|}
\hline No. & $\begin{array}{l}\text { Dosis } \mathrm{NaClO} \\
\text { (mg/L) }\end{array}$ & $\begin{array}{l}\text { Nilai Klorin } \\
\text { Bebas (mg/L) }\end{array}$ & $\begin{array}{l}\text { Bakteri } \\
\text { Koliform Pada } \\
\text { Blanko }\end{array}$ & $\begin{array}{l}\text { Bakteri } \\
\text { Koliform Pada } \\
\text { Konsentrasi } \\
\text { Dosis Optimum }\end{array}$ \\
\hline 1. & 3,5 & 0,66 & - & - \\
\hline 2. & 4 & 0,70 & - & - \\
\hline 3. & 4,5 & 0,76 & - & - \\
\hline 4. & 5,5 & 0,79 & 3000 & 300 \\
\hline 5. & 6 & 0,82 & - & - \\
\hline
\end{tabular}

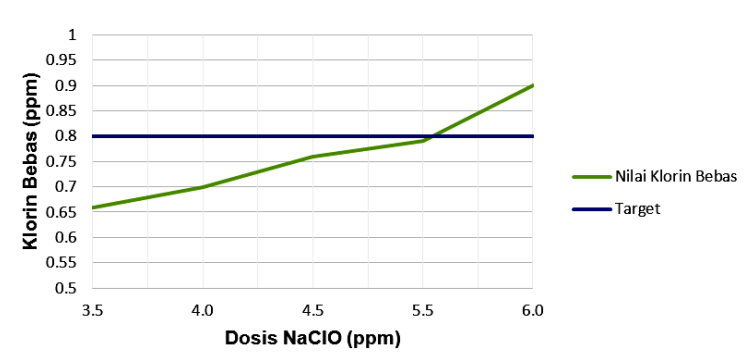

Gambar 3.

Grafik Hasil Penelitian Tahap Kedua dari Trial Ke-1

Berdasarkan hasil Penelitian tahap kedua pada Trial 2 menunjukkan bahwa nilai klorin bebas yang dihasilkan sebesar $0,78 \mathrm{mg} / \mathrm{L}$ berada pada dosis $\mathrm{NaClO}$ sebesar $6 \mathrm{mg} / \mathrm{L}$. Dengan demikian dosis optimum yang ditetapkan pada Trial 2 sebesar $6 \mathrm{mg} / \mathrm{L}$. Di bawah ini dapat dilihat hasil penelitian tahap kedua dari trial ke-2.

Tabel 5.

Hasil Penelitian Tahap Kedua dari Trial Ke-2

\begin{tabular}{ccc}
\hline No. & $\begin{array}{c}\text { Dosis NaClO } \\
(\mathbf{m g} / \mathbf{L})\end{array}$ & $\begin{array}{c}\text { Nilai Klorin } \\
\text { Bebas (mg/L) }\end{array}$ \\
\hline 1. & 5 & 0,76 \\
2. & 6 & 0,78 \\
3. & 7 & 0,85 \\
4. & 8 & 0,87 \\
5. & 9 & 0,89 \\
\hline
\end{tabular}




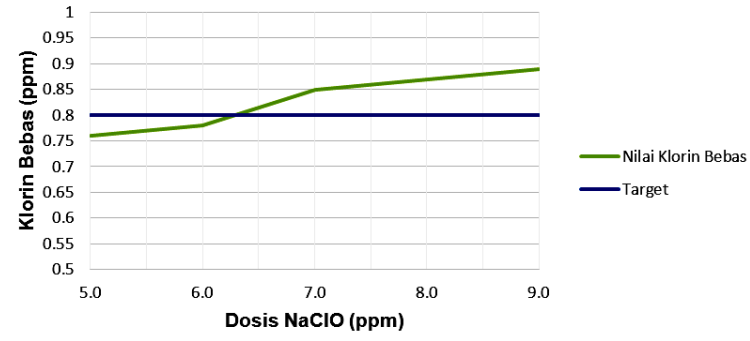

Gambar 4.

Grafik Hasil Penelitian Tahap Kedua Dari Trial Ke-2

Berdasarkan hasil Penelitian tahap kedua pada Trial 3 menunjukkan bahwa nilai klorin bebas yang dihasilkan sebesar $0,78 \mathrm{mg} / \mathrm{L}$ berada pada dosis $\mathrm{NaClO}$ sebesar $7 \mathrm{mg} / \mathrm{L}$. Dengan demikian, dosis optimum yang ditetapkan pada Trial 2 sebesar $7 \mathrm{mg} / \mathrm{L}$. Di bawah ini dapat dilihat hasil penelitian tahap kedua dari trial ke-3.

Tabel 6.

Hasil Penelitian Tahap Kedua dari Trial Ke-3

\begin{tabular}{ccc}
\hline No. & $\begin{array}{c}\text { Dosis NaClO } \\
(\mathbf{m g} / \mathbf{L})\end{array}$ & $\begin{array}{c}\text { Nilai Klorin } \\
\text { Bebas }(\mathbf{m g} / \mathbf{L})\end{array}$ \\
\hline 1. & 5 & 0,70 \\
2. & 6 & 0,73 \\
3. & 7 & 0,78 \\
4. & 8 & 0,81 \\
5. & 9 & 0,85 \\
\hline
\end{tabular}

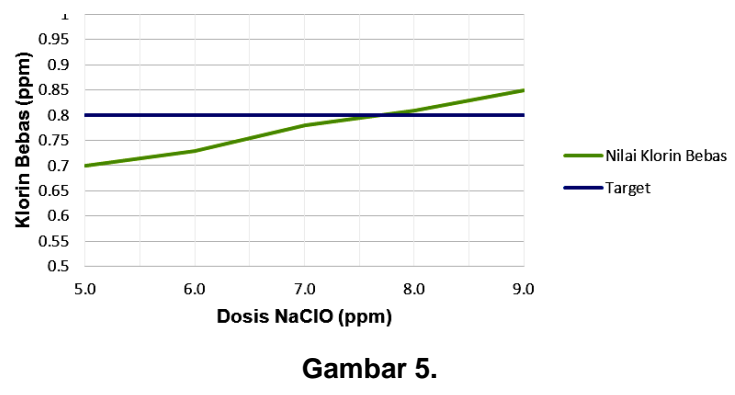

Grafik Hasil Penelitian Tahap Kedua Dari Trial Ke-3
Berdasarkan hasil Penelitian tahap kedua pada Trial 4 menunjukkan bahwa nilai klorin bebas yang dihasilkan sebesar $0,74 \mathrm{mg} / \mathrm{L}$ berada pada dosis $\mathrm{NaClO}$ sebesar $2 \mathrm{mg} / \mathrm{L}$. Dengan demikian, dosis optimum yang ditetapkan pada Trial 2 sebesar $2 \mathrm{mg} / \mathrm{L}$. Di bawah ini dapat dilihat hasil penelitian tahap kedua dari trial ke-4 .

Tabel 7.

Hasil Penelitian Tahap Kedua dari Trial Ke-4

\begin{tabular}{ccc}
\hline No. & $\begin{array}{c}\text { Dosis NaClO } \\
(\mathbf{m g} / \mathbf{L})\end{array}$ & $\begin{array}{c}\text { Nilai Klorin } \\
\text { Bebas }(\mathbf{m g} / \mathbf{L})\end{array}$ \\
\hline 1. & 1,5 & 0,73 \\
2. & 2 & 0,74 \\
3. & 3 & 0,84 \\
4. & 3,5 & 0,85 \\
5. & 4,5 & 0,91 \\
\hline
\end{tabular}

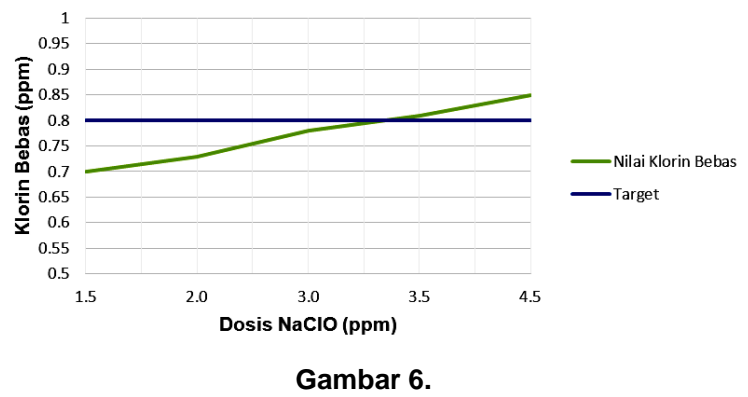

Grafik Hasil Penelitian Tahap Kedua Dari Trial Ke-4

Berdasarkan hasil penelitian tahap kedua pada Trial 5 menunjukkan bahwa nilai klorin bebas yang dihasilkan sebesar $0,78 \mathrm{mg} / \mathrm{L}$ berada pada dosis $\mathrm{NaClO}$ sebesar $6 \mathrm{mg} / \mathrm{L}$. Dengan demikian, dosis optimum yang ditetapkan pada Trial 2 sebesar $6 \mathrm{mg} / \mathrm{L}$. Di bawah ini dapat dilihat hasil penelitian tahap kedua dari trial ke-5. 
Tabel 8.

Hasil Penelitian Tahap Kedua Trial Ke-5

\begin{tabular}{ccc}
\hline No. & $\begin{array}{c}\text { Dosis NaClO } \\
(\mathbf{m g} / \mathbf{L})\end{array}$ & $\begin{array}{c}\text { Nilai Klorin } \\
\text { Bebas }(\mathbf{m g} / \mathbf{L})\end{array}$ \\
\hline 1. & 5 & 0,76 \\
2. & 6 & 0,78 \\
3. & 7 & 0,83 \\
4. & 8 & 0,84 \\
5. & 9 & 0,91 \\
\hline
\end{tabular}

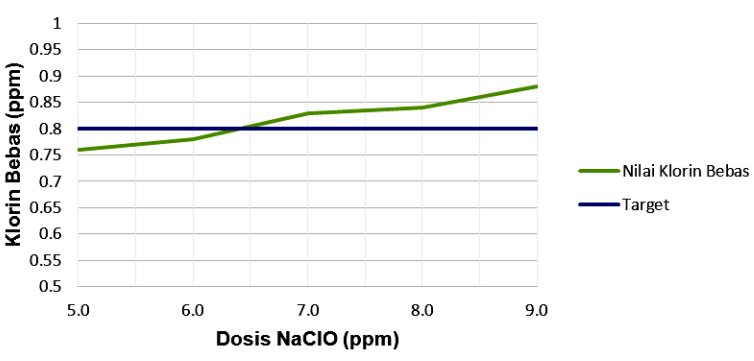

Gambar 7.

Grafik Hasil Penelitian Tahap Kedua Dari Trial Ke-5

Berdasarkan hasil Penelitian tahap kedua pada Trial 6 menunjukkan bahwa nilai klorin bebas yang dihasilkan sebesar $0,77 \mathrm{mg} / \mathrm{L}$ berada pada dosis $\mathrm{NaClO}$ sebesar $3,5 \mathrm{mg} / \mathrm{L}$. Dengan demikian, dosis optimum yang ditetapkan pada Trial 2 sebesar 3,5 mg/L. Di bawah ini dapat dilihat hasil penelitian tahap kedua dari trial ke-6.

Tabel 9.

Hasil Penelitian Tahap Kedua Trial Ke-6

\begin{tabular}{ccc}
\hline No. & $\begin{array}{c}\text { Dosis NaClO } \\
(\mathbf{m g} / \mathbf{L})\end{array}$ & $\begin{array}{c}\text { Nilai Klorin } \\
\text { Bebas }(\mathbf{m g} / \mathbf{L})\end{array}$ \\
\hline 1. & 1,5 & 0,59 \\
2. & 2 & 0,63 \\
3. & 3 & 0,71 \\
4. & 3,5 & 0,77 \\
5. & 4,5 & 0,86 \\
\hline
\end{tabular}

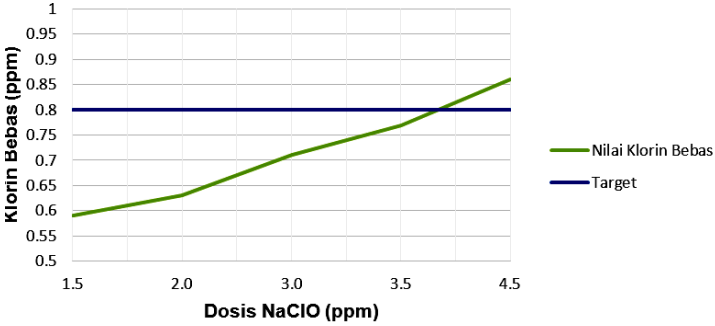

Gambar 8.

Grafik Hasil Penelitian Tahap Kedua Dari Trial Ke-6

Berdasarkan hasil Penelitian tahap kedua pada Trial 7 menunjukkan bahwa nilai klorin bebas yang dihasilkan sebesar $0,78 \mathrm{mg} / \mathrm{L}$ berada pada dosis $\mathrm{NaClO}$ sebesar $7 \mathrm{mg} / \mathrm{L}$. Dengan demikian, dosis optimum yang ditetapkan pada Trial 2 sebesar $7 \mathrm{mg} / \mathrm{L}$. Di bawah ini dapat dilihat hasil penelitian tahap kedua dari trial ke-7.

Tabel 10.

Hasil Penelitian Tahap Kedua Trial Ke-7

\begin{tabular}{lll}
\hline No. & $\begin{array}{l}\text { Dosis NaClO } \\
(\mathbf{m g} / \mathbf{L})\end{array}$ & $\begin{array}{l}\text { Nilai Klorin } \\
\text { Bebas }(\mathbf{m g} / \mathbf{L})\end{array}$ \\
\hline 1. & 5 & 0,72 \\
2. & 6 & 0,76 \\
3. & 7 & 0,78 \\
4. & 8 & 0,81 \\
5. & 9 & 0,94 \\
\hline
\end{tabular}

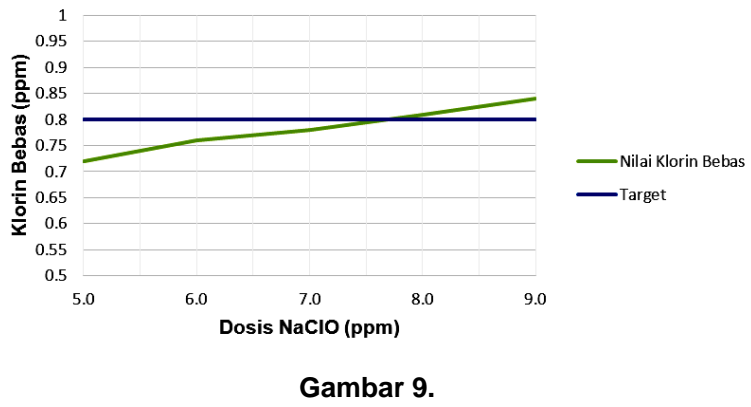

Grafik Hasil Penelitian Tahap Kedua Dari Trial Ke-7 
Berdasarkan hasil Penelitian tahap kedua pada Trial 8 menunjukkan bahwa nilai klorin bebas yang dihasilkan sebesar $0,76 \mathrm{mg} / \mathrm{L}$ berada pada dosis $\mathrm{NaClO}$ sebesar $5 \mathrm{mg} / \mathrm{L}$. Dengan demikian, dosis optimum yang ditetapkan pada Trial 2 sebesar $5 \mathrm{mg} / \mathrm{L}$. Di bawah ini dapat dilihat hasil penelitian tahap kedua dari trial ke-8.

Tabel 11.

Hasil Penelitian Tahap Kedua Trial Ke-8

\begin{tabular}{ccc}
\hline No. & $\begin{array}{c}\text { Dosis NaClO } \\
(\mathbf{m g} / \mathbf{L})\end{array}$ & $\begin{array}{c}\text { Nilai Klorin } \\
\text { Bebas }(\mathbf{m g} / \mathbf{L})\end{array}$ \\
\hline 1. & 5 & 0,76 \\
2. & 6 & 0,82 \\
3. & 7 & 0,87 \\
4. & 8 & 0,90 \\
5. & 9 & 0,92 \\
\hline
\end{tabular}

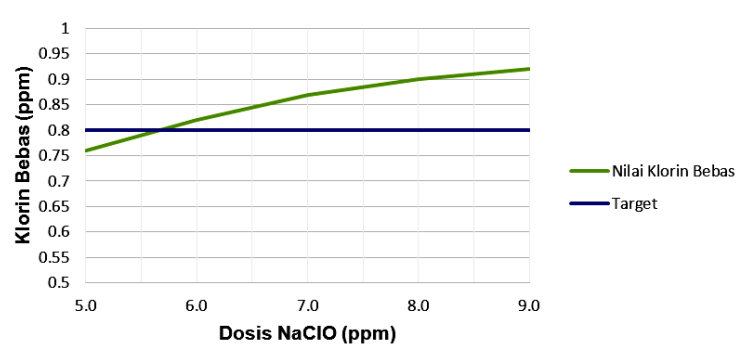

Gambar 10.

Grafik Hasil Penelitian Tahap Kedua Dari Trial Ke-8

Berdasarkan hasil Penelitian tahap kedua pada Trial 9 menunjukkan bahwa nilai klorin bebas yang dihasilkan sebesar $0,77 \mathrm{mg} / \mathrm{L}$ berada pada dosis $\mathrm{NaClO}$ sebesar $6 \mathrm{mg} / \mathrm{L}$. Dengan demikian, dosis optimum yang ditetapkan pada Trial 2 sebesar $6 \mathrm{mg} / \mathrm{L}$. Di bawah ini dapat dilihat hasil penelitian tahap kedua dari trial ke-9.
Tabel 12.

Hasil Penelitian Tahap Kedua Trial Ke-9

\begin{tabular}{lll}
\hline No. & $\begin{array}{l}\text { Dosis NaClO } \\
(\mathrm{mg} / \mathrm{L})\end{array}$ & $\begin{array}{l}\text { Nilai Klorin Bebas } \\
(\mathrm{mg} / \mathrm{L})\end{array}$ \\
\hline 1. & 5 & 0,72 \\
2. & 6 & 0,77 \\
3. & 7 & 0,81 \\
4. & 8 & 0,92 \\
5. & 9 & 1,03 \\
\hline
\end{tabular}

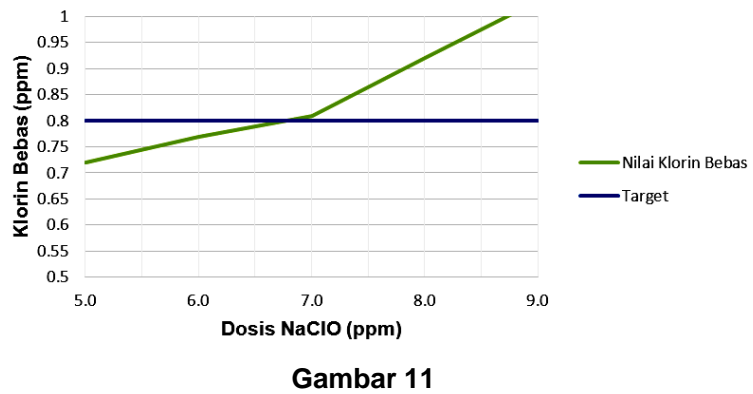

. Grafik Hasil Penelitian Tahap Kedua Dari Trial Ke-9

Dosis Optimum dalam penambahan Natrium Hipoklorit $(\mathrm{NaClO})$ ke IPAL PT Merck Tbk. dapat ditentukan dari hasil Penelitian skala laboratorium dengan metode Jartest. Dari penjelasan sebelumnya tentang hasil Penelitian tahap kedua dapat ditarik kesimpulan dosis optimum dari masingmasing Trial. Nilai dosis optimum yang akan diambil adalah konsentrasi penambahan $\mathrm{NaClO}$ terbesar yang menghasilkan nilai klorin bebas kurang dari sama dengan $0,8 \mathrm{mg} / \mathrm{L}$. Penetapan nilai klorin bebas sebesar $0,8 \mathrm{mg} / \mathrm{L}$ merupakan target penelitian sebagai safety factor terhadap sistem dengan baku mutu klorin bebas yang berlaku. Hasil konsentrasi dosis optimum dari masing-masing Trial terlihat hasil yang variatif. Hal tersebut dapat 
terjadi dikarenakan kualitas dan kuantitas air limbah yang masuk ke sistem IPAL berbedabeda tiap harinya, sehingga konsentrasi dosis optimum yang dihasilkan berbeda-beda.

Tabel 13.

\section{Konsentrasi Dosis Optimum Tiap Penelitian Tahap} Kedua

\begin{tabular}{lll}
\hline No. & $\begin{array}{l}\text { Dosis Optimum } \\
\text { NaClO (mg/L) }\end{array}$ & $\begin{array}{l}\text { Nilai Klorin } \\
\text { Bebas }(\mathbf{m g} / \mathbf{L})\end{array}$ \\
\hline 1. & 5,5 & 0,79 \\
2. & 6 & 0,78 \\
3. & 7 & 0,78 \\
4. & 2 & 0,74 \\
5. & 6 & 0,78 \\
6. & 3,5 & 0,77 \\
7. & 7 & 0,78 \\
8. & 5 & 0,76 \\
9. & 6 & 0,77 \\
\hline
\end{tabular}

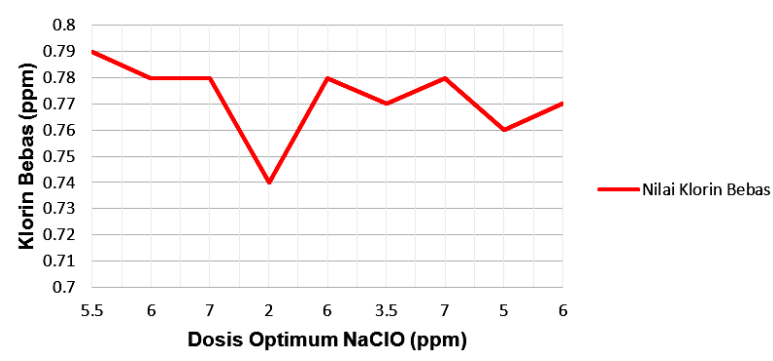

Gambar 12.

Grafik Dosis Optimum Dari Tiap Penelitian Tahap Kedua

Tabel 14.

Hasil Software SPSS

\begin{tabular}{cccc}
\hline $\mathbf{R}$ & $\begin{array}{c}\mathbf{R} \\
\text { Square }\end{array}$ & $\begin{array}{c}\text { Adjusted } \\
\text { R Square }\end{array}$ & $\begin{array}{c}\text { Std. Error } \\
\text { of the } \\
\text { Estimated }\end{array}$ \\
\hline 0,789 & 0,623 & 0,569 & 0,00972 \\
\hline
\end{tabular}

Dari konsentrasi dosis optimum dan nilai klorin bebas yang didapat, kemudian dilakukan analisa statistik dengan program SPSS dengan hasil seperti pada Tabel 14 diatas. Dari hasil analisa statistik yang dilakukan, didapat nilai regresi (R) sebesar 0,789. Hal ini dapat diartikan bahwa hubungan kedua variabel antara dosis klorin dengan klorin bebas bersifat kuat yang berarti terdapat hubungan yang kuat dengan kenaikan dosis klorin.

Bila ditinjau dari nilai koefisien determinasi $\left(R^{2}\right)$ dari hasil analisa statistik yang dilakukan memiliki nilai sebesar 62,3\%, artinya presentase pengaruh dosis klorin terhadap nilai klorin bebas sebesar $62,3 \%$ dan $37,7 \%$ nya dipengaruhi oleh faktor lain. Faktor lain yang mempengaruhi nilai klorin bebas yaitu karakteristik dari air limbah itu sendiri. Hal ini terbukti dari hasil niai klorin pada penelitian tahap awal yang dilakukan, dimana pada penelitian tahap awal untuk konsentrasi 0 $\mathrm{mg} / \mathrm{L}$ (sampel blanko) sudah memiliki nilai klorin bebas yang berkisar antara 0,41 mg/L sampai $0,68 \mathrm{mg} / \mathrm{L}$. Pada Tabel 15 disajikan nilai klorin bebas pada konsentrasi $0 \mathrm{mg} / \mathrm{L}$ dari penelitian tahap awal.

Tabel 15.

Nilai Klorin Bebas Pada Konsentrasi 0 mg/L

\begin{tabular}{ccc}
\hline No. & Penelitian & $\begin{array}{c}\text { Nilai Klorin } \\
\text { Bebas (mg/L) }\end{array}$ \\
\hline 1. & Trial 1 & 0,48 \\
2. & Trial 2 & 0,51 \\
3. & Trial 3 & 0,52 \\
4. & Trial 4 & 0,68 \\
5. & Trial 5 & 0,61 \\
6. & Trial 6 & 0,52 \\
7. & Trial 7 & 0,55 \\
8. & Trial 8 & 0,49 \\
9. & Trial 9 & 0,53 \\
\hline
\end{tabular}




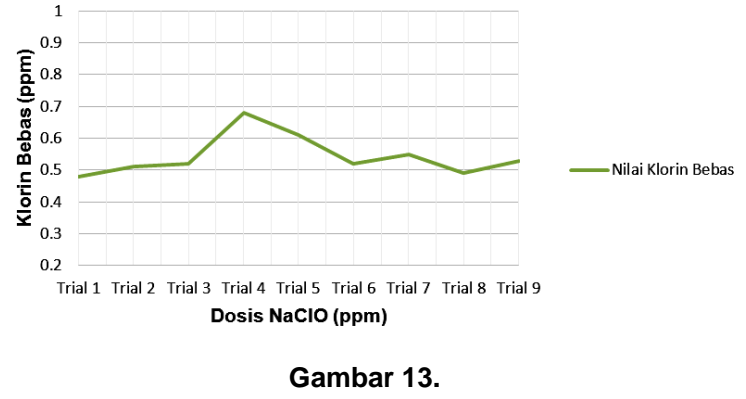

Grafik Nilai Klorin Bebas Pada Konsentrasi 0 mg/L

Berdasarkan nilai dosis optimum dari masingmasing penelitian seperti pada tabel 15, dapat ditarik kesimpulan untuk konsentrasi dosis optimum yang akan digunakan sebagai pembubuhan Natrium Hipoklorit ( $\mathrm{NaClO}$ ) pada Instalasi Pengolahan Air Limbah (IPAL). Adalah $6 \mathrm{mg} / \mathrm{L}$. Pemilihan konsentrasi klorin 6 $\mathrm{mg} / \mathrm{L}$ sebagai dosis optimum karena pada dosis tersebut merupakan nilai yang sering muncul untuk ditentukan dosis optimum pada penelitian tahap kedua yang telah dilakukan.

Tahap kedua lainnya terdapat pula konsentrasi dosis optimum yang ditetapkan kurang dari $6 \mathrm{mg} / \mathrm{L}$ pada trial ke-4 dan ke- 6 yaitu pada konsentrasi $2 \mathrm{mg} / \mathrm{L}$ dan $3,5 \mathrm{mg} / \mathrm{L}$. Pada konsentrasi tersebut tidak penulis tetapkan sebagai simpulan akhir dosis optimum karena kualitas air limbah yang diolah bervariasi tiap harinya, sehingga bila ditetapkan konsentrasi dosis optimum penelitian pada $2 \mathrm{mg} / \mathrm{L}$ ditakutkan masih belum dapat menurunkan bakteri koliform karena selain klorin bereaksi dengan mikroorganisme, klorin juga dapat bereaksi dengan zat organik dan zat anorganik lainnya.

Tabel 16.

Nilai Klorin Bebas Pada Konsentrasi 6 mg/L

\begin{tabular}{ccc}
\hline No. & Penelitian & $\begin{array}{c}\text { Nilai Klorin } \\
\text { Bebas }(\mathbf{m g} / \mathbf{L})\end{array}$ \\
\hline 1. & Trial 1 & 0,82 \\
2. & Trial 2 & 0,78 \\
3. & Tria/3 & 0,73 \\
4. & Trial 4 & - \\
5. & Trial 5 & 0,78 \\
6. & Trial 6 & - \\
7. & Trial 7 & 0,76 \\
8. & Trial 8 & 0,82 \\
9. & Trial 9 & 0,77 \\
\hline
\end{tabular}

Berdasarkan nilai klorin bebas yang dihasilkan pada konsentrasi $\mathrm{NaClO}$ sebesar $6 \mathrm{mg} / \mathrm{L}$ seperti pada tabel 16, menunjukkan bahwa nilai klorin bebas yang dihasilkan berkisar antara 0,73 mg/L sampai 0,82 $\mathrm{mg} / \mathrm{L}$. Hal tersebut dapat disimpulkan bahwa konsentrasi dosis optimum yang ditetapkan penulis sebesar $6 \mathrm{mg} / \mathrm{L}$ masih menghasilkan rentang nilai klorin bebas yang sesuai dengan target peneliti. Namun, pada penelitian ke-4 dan ke-6 hanya dilakukan penelitian tahap kedua sampai pada konsentrasi dosis klorin 4,5 $\mathrm{mg} / \mathrm{L}$ saja karena saat penelitian tahap 
pertama pada konsentrasi $5 \mathrm{mg} / \mathrm{L}$ sudah menghasilkan nilai klorin bebas yang melebihi target penulis. Hal tersebut terjadi karena sampel air limbah yang diuji pada saat penelitian ke-4 dan ke- 6 dalam kondisi tidak berwarna. Karena pada penelitian sebelumnya yang dilakukan oleh Mohamadreza Massoudinejad didapat hasil bahwa terdapat hubungan antara warna dengan konsentrasi penambahan klorin. Mohamadreza Massoudinejad pada tahun 2015 melakukan penelitian penghilangan warna dan COD pada industri tekstil dengan hipoklorit.

\section{KESIMPULAN}

Berdasarkan dari penelitian skala laboratorium yang dilakukan untuk menentukan dosis optimum dalam penambahan Natrium Hipoklorit ( $\mathrm{NaClO})$ pada IPAL dapat disimpulkan bahwa:

1. Dari penelitian skala laboratorium yang telah dilakukan terdapat dosis optimum yang bervariasi pada tiap penelitiannya. Hal ini dikarenakan kualitas dan kuantitas air limbah yang masuk ke sistem Instalasi Pengolahan Air Limbah Perusahaan/Industri Farmasi. bervariasi tiap harinya.

2. Dosis optimum yang didapat dari penelitian skala laboratorium adalah sebesar $6 \mathrm{mg} / \mathrm{L}$ dan dapat menurunkan jumlah bakteri koliform menjadi 300 jumlah/100 mL.

3. Hasil analisa statistik dengan Software SPSS yang menghubungkan antara dosis klorin yang ditambahkan dengan nilai klorin bebas yang dihasilkan memiliki nilai sebesar 0,789 yang berarti terdapat hubungan yang kuat antara bertambahnya dosis klorin dengan meningkatnya pula nilai klorin bebas yang dihasilkan.

\section{DAFTAR PUSTAKA}

[1] Crisnaningtyas, F., Vistanty, H. 2016. Pengolahan Limbah Cair Industri Farmasi Formulasi dengan Metode AnaerobKoagulasi, Jurnal Riset Teknologi Pencegahan Pencemaran Industri, Vol. 7 No. 1, pp. 13-22.

[2] Yustiani, Y.M. 2016. Determination of Deoxygenation Rate of Rivers Located in the Urban Areas to Characterize the Pollutants, Pollution Research, 35 (3), pp. $475-481$.

[3] Yustiani, Y.M., Lidya, L., Matsumoto, T. Rachman, I., Komariah, I. 2017. Formulation of the Integrated Information System of River Water Quality in the Cikapundung River, Bandung, Indonesia, International Journal of Engineering and Technology, Vol. 9 (1), pp. 137-142. 
Infomatek Volume 23 Nomor 1 Juni 2021 : 27 - 42

[4] Meirdana, S., Utomo, S. 2021. Studi kasus Pengelolaan Lingkungan Berkelanjutan, evaluasi penaatan aspek pengolahan Journal of Environmental Sustainability limbah cair industri farmasi. Jurnal Management, Vol. 4(3), pp. 592-603. 